\title{
Levodopa/carbidopa and entacapone in the treatment of Parkinson's disease: efficacy, safety and patient preference
}

\author{
Thomas Müller ${ }^{1,2}$ \\ 'Department of Neurology, \\ St. Joseph Hospital Berlin-Weißensee, \\ Berlin, Germany; ${ }^{2} I G S N$, \\ Ruhr University of Bochum, \\ Bochum, Germany
}

\begin{abstract}
Levodopa (LD) is the oldest, most efficacious and best-tolerated drug for dopaminergic substitution of patients with Parkinson's disease (PD). Its main drawback is its short half-life, which supports onset of motor complications in the long term. Therefore well-informed PD patients mostly accept LD therapy as late as possible. Recent LD trials indicate that a combination of LD with carbidopa (CD) and the catechol-O-methyltransferase (COMT) inhibitor entacapone (EN) may reduce the onset of these motor complications to a certain extent. This observation is further supported by pharmacokinetic trials and experimental research, but there is still a need to confirm this in a clinical trial, which is under way. Additionally, combined LD/CD/EN was superior to $\mathrm{LD} / \mathrm{CD}$ administration regarding cognition, muscle behavior and gastrointestinal function in small clinical trials. Moreover there is accumulating evidence that combined COMT inhibition with LD administration reduces homocysteine synthesis. In the long term, homocysteine elevation supports onset of arteriosclerosis-related disorders, which are more frequent in PD patients according to epidemiological studies than in the normal healthy population. The introduction of $\mathrm{LD} / \mathrm{CD} / \mathrm{EN}$ in one tablet supported patients' preference of COMT inhibition as an essential component of LD/DDI therapy, as this combination reduced number and size of tablets.
\end{abstract}

Keywords: levodopa, entacapone, Parkinson's disease, preference, compliance, acceptance

\section{Introduction}

The oldest, most efficacious and best tolerated drug for dopaminergic substitution therapy of patients with Parkinson's disease (PD) is levodopa (LD). Initially LD was administered as infusion, then in oral form. ${ }^{2,3} \mathrm{LD}$ administration was improved by the addition of the dopadecarboxylase inhibitors (DDI), such as carbidopa (CD), which reduces the peripheral degradation of $\mathrm{LD}$ to dopamine. This therapeutic principle supports LD metabolism via the enzyme catechol-O-methyltransferase (COMT) and delivers more $\mathrm{LD}$ to the brain.

\section{LD/DDI and COMT inhibition}

A further development was the introduction of COMT inhibitors, which decrease peripheral LD degradation to 3-O-methyldopa (3-OMD) and thus further increase the delivery of LD to the brain. ${ }^{4,5}$ Two COMT-inhibitors, the only peripheral-acting entacapone (EN) and the additionally central-acting tolcapone, ${ }^{6,7}$ are currently marketed as adjuncts to LD/DDI application. Both prolong the half-life of LD in the periphery.

\section{Important clinical trials on the efficacy of LD in PD patients}

Out of the many investigations that demonstrated the efficacy of LD, the Earlier vs Later L-DOPA (ELLDOPA) trial was the first double blind trial, which compared the 
therapeutic efficacy of LD/CD in 3 different daily dosages of $150 \mathrm{mg}, 300 \mathrm{mg}$ or $600 \mathrm{mg}$ with placebo treatment according to the guidelines of good clinical practice (GCP) in PD patients. This trial confirmed that LD is an efficacious and well tolerated compound. Interestingly, this study also provided some evidence for progression-modifying benefits of LD in PD patients despite its relative short duration of approximately 9 months. After a washout interval of 14 days, the three cohorts of LD-treated PD patients performed better than the ones with prior placebo treatment. There is some evidence from experimental and clinical outcomes that the peripheral dual inhibition of both LD-metabolizing enzymes increases the LD delivery to the brain compared to LD/CD. ${ }^{8}$ A further GCP trial on LD/CD efficacy, the FIRST-STEP (Favorability of Immediate-Release Levodopa/Carbidopa vs STalevo Short-Term comparison in Early Parkinson's disease) study, compared the efficacy of 2 different modes of LD application, the conventional LD/CD administration versus LD/CD with the COMT inhibitor EN. ${ }^{9}$ This trial additionally aimed to demonstrate that the currently available triple combination of LD/CD plus EN in 1 tablet (Stalevo ${ }^{\circledR}$, Novartis) is safe in early PD patients with a need for LD therapy. This multicenter, double-blind, randomized, parallel-group study administered a fixed oral LD dose of $300 \mathrm{mg} /$ day, distributed as $100 \mathrm{mg}$ LD doses 3 times daily at 5-hour intervals to 424 PD patients. In this 39-week study, the PD patients in the $\mathrm{LD} / \mathrm{CD} / \mathrm{EN}$ arm performed significantly better than the ones in the LD/CD-treated cohort after week four throughout the remaining course of the study. This was found when the sum scores of the UPDRS part II (Activities of daily living) and UPDRS part III (motor examination) were compared as the main primary outcome at the remaining study visits. The statistical analysis was performed with the intention to treat population and employed the last observation carried forward procedure. The frequency of nausea and diarrhea was higher in the $\mathrm{LD} / \mathrm{CD} / \mathrm{EN}$ arm due to the additional COMT inhibition with particularly diarrhea as a common side-effect. ${ }^{9}$ Thus the FIRST-STEP trial confirmed the known additional LD/DDI efficacy-enhancing effects of EN, when given as extra tablet, to an existing $\mathrm{LD} / \mathrm{CD}$ regimen in treated $\mathrm{PD}$ patients. ${ }^{10}$ However the design of the FIRST-STEP study lacked comparisons with placebo and treatment with dopamine agonists. One must realize that $300 \mathrm{mg} \mathrm{LD} / \mathrm{CD}$ are not comparable to $300 \mathrm{mg} \mathrm{LD} / \mathrm{CD} / \mathrm{EN}$, since the additional COMT inhibition with EN delivers more LD to the brain and thus improves the clinical efficacy of LD.

However both studies, FIRST-STEP and ELLDOPA, provide also some interesting findings about the onset and frequency of fluctuating disturbances of motor behavior, the so called motor complications, in PD patients. These symptoms are a serious drawback of LD therapy, and induce a lot of concern in PD patients and their caregivers and considerably limit the acceptance of this compound.

\section{Limitations of LD/DDI administration}

There is a debate around mainly the clinical observation of the onset of fluctuations of movement in the course of PD following the so called "honeymoon period" of LD therapy. Motor complications are predominantly associated with LD/DDI due to the short half-life of LD. They are looked upon as one essential clinical marker for the progression of PD. Peaks and troughs of plasma levels of LD and thus correspondingly central striatal dopamine concentrations support occurrence of these initially predictable (which means dependent on previous PD drug intake) and later unpredictable (independent of previous PD drug application) fluctuations of movement. Clinically, they appear as involuntary motion sequences, the so-called dyskinesia, in the "ON" state. In contrast, "OFF" phenomena are characterized as temporary onset of the cardinal motor symptoms, akinesia, rigidity and tremor. They may indicate the decreasing efficacy of the last dopaminergic drug intake before the next one. Then they are characterized as wearing-off phenomena.

Both kinds of motor complications are combined with appearance of a wide array of non-motor symptoms..$^{1,1-13}$ Various central-related hypotheses exist on the origin of these LD-associated motor complications. Loss of presynaptic dopaminergic autoreceptor function with resulting non-physiologic high synaptic dopamine concentrations and consecutive altered postsynaptic dopamine receptor activation and further downstream intracellular changes currently is one of the most widely accepted hypotheses. There is accumulating evidence that continuous nigrostriatal postsynaptic dopaminergic receptor stimulation may prevent onset of motor complications. ${ }^{14}$

\section{COMT inhibition and onset of motor complications}

Additional COMT inhibition with LD/DDI application is also suspected of preventing motor complications since the rise and fall of LD and also accordingly of striatal dopamine are less intense during COMT inhibition, ie, with EN. This supports the concept of continuous dopaminergic stimulation due to a less fluctuating delivery of LD to the brain. ${ }^{11,13-16}$ Thus threshold problems of dopamine are reduced at striatal 
postsynaptic dopamine uptake sites. Therefore the frequency with which these receptors change between OFF and ON decreases. ${ }^{17-19}$ Accordingly, animal trials showed lower frequency and less intensity of manifestation of LD-associated motor complications in the long term, when a treatment with $\mathrm{LD} / \mathrm{DDI}$ with the COMT inhibitor EN, given 4 times daily, was started right from the beginning. ${ }^{18}$ Further components for response variability to additional COMT inhibition and treatment of motor complications may be genetic features of the various COMT haplotypes. But no study has shown a clinical effect of the gene variations on the onset of motor complications and on the clinical efficacy of LD. ${ }^{20,21}$

\section{Onset of motor complications in the light of the FIRST-STEP and the ELLDOPA study}

There is also some circumstantial evidence from the FIRSTSTEP and ELLDOPA study that COMT inhibition with $\mathrm{EN}$ also reduces the frequency of motor complications. The ELLDOPA study showed that the higher was the daily administered LD dose, the more frequent were motor complications. In this trial, the occurrence of motor complications were at the placebo level in the $150 \mathrm{mg}$ daily LD dose-treated cohort. However, onset of motor complications rose up to 3-fold in the $600 \mathrm{mg}$ daily dose-treated group compared with placebo-treated PD patients (Table 1). In the FIRST-STEP trial, the number of monitored motor complications was higher in the LD/CD-treated arm in comparison with the $\mathrm{LD} /$ $\mathrm{CD} / \mathrm{EN}$-treated PD cohort. It is known that less $\mathrm{LD}$ reaches the brain during $\mathrm{LD} / \mathrm{CD}$ administration in comparison with $\mathrm{LD} / \mathrm{CD} / \mathrm{EN}$ administration. Therefore onset of motor complications cannot be attributed to the LD compound itself as initially thought in discussions on the neurotoxicity of LD. This observation suggests that the application mode is essential for the onset of motor complications. However the number of noted wearing-off phenomena and dyskinesia was rather low in relation to the size of the study cohort and the short observation interval (Table 2). ${ }^{9}$ A further confirmatory result may be provided by the outcomes of the ongoing STRIDE-PD study. This trial aims to demonstrate that

Table I Frequency of motor complications in the ELLDOPA trial (\%)

\begin{tabular}{lllll}
\hline & LD/CD & LD/CD & LD/CD & \\
\cline { 2 - 4 } & $\mathbf{1 5 0} \mathbf{~ m g}$ & $\mathbf{3 0 0} \mathbf{~ m g}$ & $\mathbf{6 0 0 ~ \mathbf { ~ g }}$ & placebo \\
\hline Dyskinesia & 3.3 & 2.3 & 16.5 & 3.3 \\
Wearing off & 16.3 & 18.2 & 29.7 & 13.3 \\
\hline
\end{tabular}

Table 2 Rate of motor complications in the FIRST-STEP trial (\%)

\begin{tabular}{lllll}
\hline & LD/CD/EN & LD/CD & Total & \\
\hline Dyskinesia & 2.7 & 4.2 & 3.5 & week 39 \\
Wearing off & 8.8 & 12.0 & 10.4 & week 39 \\
Dyskinesia & 5.3 & 7.4 & 6.4 & at any study visit \\
Wearing off & 13.9 & 20 & 17 & at any study visit \\
\hline
\end{tabular}

$\mathrm{LD} / \mathrm{CD} / \mathrm{EN}$, when used as initial LD therapy, significantly delays the time to onset of dyskinesia compared with the conventional LD/CD formulation. Nevertheless the optimum approach for LD therapy in view of the concept of continuous dopaminergic stimulation is the LD patch, which failed probably due to an insufficient design or side-effects, and the jejunal LD infusion. However this latter technique is expensive, complex and needs constant caregiver supervision. Further improvement is still required, which is under way. But it is an efficacious therapeutic option for treatment of motor complications in advanced PD patients. ${ }^{16}$ Therefore a further improvement of oral drug delivery is one of the essential goals for LD/DDI therapy, as, to a considerable extent, LD efficacy also depends on peripheral absorption and degradation mechanisms of LD.

\section{Components that influence peripheral LD bioavailability}

Plasma bioavailability of LD is influenced by body weight, previous LD intake in a chronic fashion and by gastric emptying of the LD tablet to the duodenal and jejunal tract, where LD absorption takes place. ${ }^{22-25}$ But PD patients often receive a drug combination therapy that involves multiple daily dosing of a particular compound and additional supplementation with other drugs at least partially sharing the modes of action. Efficacy of all administered compounds depends on patient compliance, the nature of the delivery system, physicochemical properties of the drug and physiological considerations. All of these are interrelated and affect the rate at which the drug is absorbed throughout the gastrointestinal tract and thus its bioavailability and pharmacokinetic profile. ${ }^{26}$ In this respect EN improves the properties and dose of LD/DDI by prolonging the half-life of LD. But COMT inhibition may also promote the synthesis of more basic LD metabolites, ie, the tyrosine aminotransferasedependent substrates dihydroxyphenylpyruvate acetate and trihydroxyphenylacetate. Therefore COMT inhibition may model the environmental $\mathrm{pH}$ and the physicochemical properties of LD for its duodenal absorption. COMT is located in higher concentrations in the membranes of the 
gastrointestinal tract. ${ }^{26-30}$ Generally, these physicochemical properties of a drug also affect its absorption through the gastrointestinal tract. ${ }^{26,31}$ Compounds including LD are weak bases or weak acids or are the salts of these, and as such demonstrate $\mathrm{pH}$-dependent solubility. The $\mathrm{pH}$ partition hypothesis asserts that the passage rate of a drug through a membrane is dependent on the environmental $\mathrm{pH}$ and $\mathrm{pKa}$ of the drug. Drugs with low pKa are not ionized in the stomach and subsequently rapidly absorbed. On passage to the small intestine with comparatively increased $\mathrm{pH}$, the rate of ionization is changed and absorption subsequently slowed. The converse is true for drugs with higher $\mathrm{pKa}$ value. This influences the bioavailability of hydrophilic drug formulations. They have a narrow window of absorption, limited predominantly to the stomach or the upper intestine. Absorption is also limited by low $\mathrm{pKa}$ value and/or the site of active transport absorption mechanism, as in the case of LD. ${ }^{26,31,32}$ Additionally, absorption behavior of orally administered LD also depends on gastrointestinal transit rates, since uptake of LD occurs mainly in the proximal third of the small intestine (duodenum/jejunum) but not in the stomach. Intestinal LD absorption is rapid and complete, but the plasma bioavailability of LD is only $30 \%$ as a result of prior degradation to dopamine by DDI and to a lesser extent to 3-OMD by COMT, ie, in the gut membranes. The longer LD is retained in the stomach and in the small intestine the more extensively it is metabolized and made less available for absorption. ${ }^{25}$ A formulation that shares the peripheral absorption site profile of LD, is sodium-octanoate, which is employed as $\left[{ }^{13} \mathrm{C}\right]$ marked substrate in breath tests. These investigations are a non-invasive, feasible, alternative method without ionizing radiation to measure gastric emptying of solids and liquids. After intake, $\left[{ }^{13} \mathrm{C}\right]$-sodium-octanoate is rapidly absorbed from the proximal intestine and carried to the liver via the portal venous system. There it is oxidized and eliminated as $\mathrm{CO}_{2}$ in the breath, reflecting gastric emptying as the rate-limiting step of the process. Accordingly, significant associations between pharmacokinetic plasma behavior of $\mathrm{LD}$ and the outcomes of the $\left[{ }^{13} \mathrm{C}\right]$-octanoic acid breath test (OBT) appeared. In this study no impact of EN addition on gastric emptying time was found. But COMT inhibition with EN increased the recovery rate of the salt $\left[{ }^{13} \mathrm{C}\right]$-sodium-octanoate. ${ }^{25,29,30}$

\section{The anti-acid scenario of COMT inhibition}

It is known that medicaments are better absorbed with a rise in $\mathrm{pH}$ due to the dramatically improved solubility.
This results in a complete dissolution of the substance, which makes it readily available for absorption. ${ }^{26,32}$ Conventional LD/DDI is mainly metabolized to derivatives which lower the $\mathrm{pH}$ value. The main substrate is vanillic acid. This is formed from the initial tyrosine aminotransferasedependent derivative dihydroxyphenylpyruvate followed by a COMT-dependent second metabolic step. An alternative pathway for the formation of vanillic acid is the COMTtriggered degradation of LD to 3-OMD with a subsequent tyrosine aminotransferase-dependent second step. A further metabolite is homovanillic acid, since this depends on the initial DDI-dependent conversion to dopamine. However this LD derivative may play a minor role, since a DDI is mostly applied nowadays with LD. Dopamine is metabolized to the initial MAO-dependent dihydroxyphenylacetic acid or as an alternative to the COMT-dependent 3-methroxytyramine. Both dihydroxyphenylacetic acid via COMT and 3-methroxytyramine via monoaminooxidases are then transformed to homovanillic acid. During $\mathrm{LD} / \mathrm{CD} / \mathrm{EN}$ administration, $\mathrm{LD}$ is mainly degraded to the tyrosine aminotransferase-dependent substrates dihydroxyphenylpyruvate acetate and trihydroxyphenylacetate and to a distinctly lesser extent to dihydroxyphenylacetic acid in the periphery. ${ }^{33}$ This more basic milieu may hypothetically influence the activity of the intestinal $\mathrm{H}^{+}$-coupled nutrient, micronutrient and drug transporters in the mammalian small intestine and thus enable a better transport of acids into the peripheral blood circulation..$^{26,31,32}$ Previous studies showed no effect of acute COMT inhibition with EN on gastric emptying. But these investigations did not exclude the possibility that repeat application of EN may influence the gastric emptying rate and further increase the bioavailability of co-administered substances. ${ }^{24,25,34}$ With LD, this may cause a deteriorated degradation and result in higher LD concentrations in the gastrointestinal membranes due to the simultaneous blocking of COMT by EN and DDI by $\mathrm{CD}$. Since LD itself may contribute to delayed gastric emptying rate, this may result in the observed smoother increase of LD concentrations after repeat EN application. But these investigations support the conclusion that COMT inhibition combined with LD/DDI does not alter absorption of co-administered salts probably due to COMT inhibitioninduced basic environment in gastrointestinal membranes. This improves dissolution and absorption of acids and salts and may therefore enhance the absorption and efficacy of LD. ${ }^{24,25,34}$ It will remain speculative whether this more basic scenario may also contribute to a better patient acceptance due to a lower incidence of gastrointestinal disturbances, 
such as pyrosis. However it may also influence function of muscles.

\section{COMT inhibition and muscle function}

LD/CD application increases grip strength after standardized application and thus increases muscular strength in PD patients. $\mathrm{LD} / \mathrm{CD}$ intake counteracts muscle weakness and thus indirectly also improves grip forces during both lifting and holding of a subject in an instrumental grip force paradigm in PD patients. ${ }^{35}$ This may result from LD/CD-induced improvement of bradykinesia and rigidity. But referring to the impact of $\mathrm{LD} / \mathrm{CD}$ on grip force, $150 \mathrm{mg} \mathrm{LD} / \mathrm{CD} / \mathrm{EN}$ was superior to the $200 \mathrm{mg}$ slow release LD/CD formulation. Both LD formulations exhibited similar plasma pharmacokinetics of LD and clinical efficacy in terms of improvement of motor symptoms after standardized one time application. The $\mathrm{LD} / \mathrm{CD} / \mathrm{EN}$-associated anti-acid scenario after $\mathrm{LD} / \mathrm{CD} / \mathrm{EN}$ intake may contribute to more basic $\mathrm{pH}$ values in skeletal muscles. ${ }^{253-36}$ This may support muscle function, since generation of acidic $\mathrm{H}^{+}$ions, which are commonly attributed to the formation of organic acids such as primarily lactic acid, is buffered. As a result muscle excitability and contractibility improves. Both could have contributed to the observed augmented grip strength after $\mathrm{LD} / \mathrm{CD} / \mathrm{EN}$ intake in comparison with $\mathrm{LD} / \mathrm{CD}$ administration. ${ }^{25,34-36}$ This trial underlined the importance of COMT inhibition in addition to $\mathrm{LD} / \mathrm{CD}$ administration in $\mathrm{PD}$ patients beyond the impact of $\mathrm{LD} / \mathrm{CD}$ on motor symptoms. A further important issue is the role of the 3-OMD, when LD/DDI is given with and without COMT inhibition.

\section{COMT inhibition and 3-OMD metabolism}

COMT inhibition reduces 3-OMD plasma concentrations. This could have influenced the attention-related components of an instrumental task performance, the line tracing test. In this trial, $150 \mathrm{mg} \mathrm{LD} / \mathrm{CD} / \mathrm{EN}$ was superior to $200 \mathrm{mg}$ slow release $\mathrm{LD} / \mathrm{CD}$ after standardized one time administration. There was no rise of 3-OMD during the $\mathrm{LD} / \mathrm{CD} / \mathrm{EN}$ administration but there was after LD/CD intake. ${ }^{36}$ Therefore more $\mathrm{LD}$ was delivered to the brain during $\mathrm{LD} / \mathrm{CD} / \mathrm{EN}$ administration, since 3-OMD competes with LD during transport over the blood-brain barrier. Thus 3-OMD may interfere with the LD response by inhibiting tyrosine uptake in the striatum and subsequent LD utilization, which inhibits metabolism of LD to dopamine. ${ }^{37,38}$ It is known that small changes in catecholamine modulation of prefrontal cortex cells can have profound effects on the ability of the prefrontal cortex to guide behavior. ${ }^{39}$ Therefore this small difference of LD delivery to the prefrontal cortex could have been responsible for the described significant difference in the attentionrelated components of the line tracing task in favor of the $\mathrm{LD} / \mathrm{CD} / \mathrm{EN}$ condition. In contrast, the basal ganglia may better tolerate and compensate fluctuations of dopamine levels. However there are further metabolic aspects associated with a decreased 3-OMD synthesis, which is associated with homocysteine synthesis.

\section{LD/DDI formulations, 3-OMD and homocysteine}

LD applied only with a DDI increases homocysteine in plasma. ${ }^{40}$ This may support the onset of atherosclerosisrelated disorders, which has been shown in PD patients by epidemiological studies. ${ }^{41,42}$ To date, this LD-related homocysteine elevation has been considered as a long-term side effect in terms of onset of clinical consequences, ie, increase of vascular disease-related thickening of the intima media complex, and elevated risk of more neuropsychiatric complications, ie, depression and deteriorated cognitive function, in PD patients in earlier studies. ${ }^{43-46}$ However the outcomes of more recent trials were only partially confirmatory. ${ }^{47,48}$ This may be due to a relative low number of participants, and design and duration of these studies. Moreover the vitamin B and folic acid status and variations of the distribution of the polymorphism of the methylenetetrahydrofolate reductase (MTHFR) gene may play a role in the various investigated cohorts. In particular, the homocygote MTHFR T/T allele promotes elevated homocysteine levels. ${ }^{43,49,50}$ But one must clearly state that a relationship between homocysteine levels and deleterious consequences in $\mathrm{PD}$, for instance stroke or cognitive decline, has not been conclusively demonstrated.

\section{Therapy of homocysteine elevation with COMT inhibition}

An approach for homocysteine decrease in plasma is application of COMT inhibitors as adjunct to LD/DDI formulations, as this combination reduces $\mathrm{O}$-methylation of LD. Addition of the COMT inhibitor tolcapone to a stable antiparkinsonian drug regime reduced homocysteine plasma levels. This small prospective trial provided some evidence that COMT inhibition lowers homocysteine generation. ${ }^{51}$ In rats, this was also shown with the peripherally acting COMT inhibitor EN. ${ }^{52}$ Clinical data of EN in humans are still under discussion. There are prospective negative 
studies, but they may have been under powered because of folate supplementation in the American and Canadian diet, leading to a milder increase in homocysteine than expected. ${ }^{44,53,54}$ Observational European non-prospective studies showed lower homocysteine levels in EN-treated patients. ${ }^{5-57}$

\section{Homocysteine metabolism in relation to peripheral and central COMT inhibition}

These findings warrant a discussion about which COMT inhibitor, EN or tolcapone, is more suitable for modulating homocysteine synthesis. In contrast to the controversial results for EN acting only in the periphery, tolcapone even reduced homocysteine levels following repeated intake. ${ }^{51}$ This may indicate a certain superiority of tolcapone over $\mathrm{EN}$ in terms of impact on homocysteine metabolism. But it may also result from the different study designs used. However there is an essential pharmacological discrepancy between both compounds, since tolcapone but not EN also occurs and acts centrally. ${ }^{6,7}$ Thus tolcapone may even reduce homocysteine levels within the brain and thus the associated neurotoxic effects of homocysteine. ${ }^{58,59}$ Central COMT activation caused a sustained synthesis of homocysteine in astrocytes and transport of this amino acid to neurons. This was blocked by COMT inhibition, which was seen as neuroprotective. Moreover glial COMT reduced $\mathrm{N}$-methylation of the dopamine derivative salsolinol to $\mathrm{N}$-methylsalsolinol or of the tetrahydroisoquinolines (TIQ) to the corresponding neurotoxic $\mathrm{N}$-methylisoquinolinium ions. ${ }^{60-62}$ Therefore central COMT inhibition may turn out to be a double-edged sword, since the broad detoxification potential of COMT within the brain is reduced. Thus exclusive central COMT inhibition may also force central dopamine degradation to metabolism via monoaminooxidase B, which generates oxidative stress. Therefore oxidative stress was found in combination with S-adenosylmethionine (SAM) depletion, as SAM is the methyl donor for nicotinamide N-methylation and most other important methylation reactions. ${ }^{7,61,63-66}$ Accordingly, reduced SAM levels were found in chronic neurodegeneration. ${ }^{67-70} \mathrm{LD} / \mathrm{DDI}$ further lowered SAM concentrations, ${ }^{71}$ as O-methylation of LD by COMT elevates homocysteine. ${ }^{58,64,72}$ Consequently, one may suggest combining central COMT inhibition with central blocking of monoaminooxidase-B. This may increase the generation of free radicals via monoaminooxidase A-induced dopamine degradation. Moreover this may further promote the shift from O-methylation to
$\mathrm{N}$-methylation, and a cumulative metabolism of dopamine and other substrates via $\mathrm{N}$-methylating enzymes. As a result, an increment of neurotoxic N-methylated TIQs synthesis may occur, as shown in clinical studies. ${ }^{73,74}$ Only LD/DDI-treated but not untreated PD patients showed increased levels of N-methylated TIQs, but not of their corresponding metabolic precursors. ${ }^{75-78}$ Thus in conclusion this increased risk of PD accelerating synthesis of free radicals and N-methylated TIQs associated with central COMT inhibition may suggest peripheral COMT inhibition as adjunct for LD/DDI therapy. This may also underline the safety of EN in the treatment of PD patients, which is one of the essentials for accepting the intake of a compound in the long term.

\section{The safety of EN long-term application}

Numerous trials and reviews have proven and reported the long-erm tolerability and safety of EN treatment in PD patients. The introduction of the triple combination LD/ $\mathrm{CD} / \mathrm{EN}$ in one tablet is also safe and efficacious. Combined EN application with selegiline, dopamine agonists and antidepressants such as imipramine was well tolerated. ${ }^{79-89}$ Observed discoloration of the urine is harmless, but the patient should be informed before start of therapy by the treating physician. In contrast there was always a certain debate about putative peripheral and central toxic effects of tolcapone. ${ }^{63}$ This was followed by reports that tolcapone causes onset of serious hepatic reactions with development of severe, sometimes fatal, hepatic disease as well as possible occurrence of rhabdomyolysis and neuroleptic malignant-like syndrome. One assumes that patients with mutations in the UDPglucuronosyltransferase 1A9 gene, which leads to defective glucuronidation activity, may be predisposed to COMT inhibitor-induced hepatotoxicity. ${ }^{90}$ Therefore tolcapone was temporarily withdrawn nearly all over the world. The most frequent non-dopaminergic adverse event of COMT inhibition was diarrhea, usually 2 to 4 months following treatment initiation. This may be due to the inhibition of 5-HT metabolism in the gastrointestinal tract, which causes an increase of gastrointestinal motility in some PD patients. ${ }^{4,5}$ Headache, increased sweating and associated xerostoma probably due to aggravation of dyskinesia in clinical trials, abdominal pain, and harmless urine discoloration are more frequently reported than in the placebo arm in clinical trials that tested the efficacy of COMT inhibitors. But the discussion on the liver toxicity of tolcapone with a demand for regular liver function tests also biased the patients' preference for 
EN intake. An additional negative criterion for tolcapone use is the need for a previous failed response to $\mathrm{EN}$ or intolerance of intake of other COMT inhibitors.

\section{Aspects of patient preference for LD/CD combined with EN intake}

Treatment of PD often requires intake of an increasing number of tablets with progression of the disease, which results in compliance problems. Therefore discipline and education of patients and their caregivers are essential tools to minimize any behavior that might limit the efficacy of compounds. ${ }^{91,92}$ Advanced PD patients must often take LD doses more frequently (LD "fractionation") and as continuously as possible, since fluctuations of plasma LD levels and accordingly motor performance should be reduced. In this regard the introduction of the triple combination $\mathrm{LD} / \mathrm{CD} / \mathrm{EN}$ in one tablet was an essential step forward in contrast to the older LD/DDI plus EN administration as an extra tablet. Now oral LD/CD/EN therapy requires intake of half the number of tablets. Moreover the pills of the LD/CD/EN formulation are distinctly smaller, which favors patients' acceptance. A remaining drawback is the availability of this combination in only a few LD dosages, which limits the titration possibilities for the physician in comparison with $\mathrm{LD} / \mathrm{CD}$. This drawback should be remedied in the near future with the necessary introduction of $25 \mathrm{mg}, 75 \mathrm{mg}, 125 \mathrm{mg}$, $175 \mathrm{mg} \mathrm{LD} / \mathrm{CD} / \mathrm{EN}$ formulations. However for titration speed, efficacy and tolerability $\mathrm{LD} / \mathrm{CD} / \mathrm{EN}$ is superior to that of dopamine agonists, which still have the advantage of delaying the time to onset of motor complications, as proven by numerous studies and reviews. ${ }^{93,94}$ But one must realize that there is still a lack of data on patient preference and of comparative studies on other forms of LD, such as controlled-release formulations, on infusion application modes and on dopamine agonists.

\section{Conclusion}

Additional peripheral COMT inhibition with EN is an improvement on LD/DDI administration in PD patients. It contributes to a better cognition, muscle force and movement behavior performance according to clinical outcomes. There is some evidence that peripheral COMT inhibition also delays onset of motor complications and supports occurrence of lower homocysteine plasma levels, which, when elevated, represent a risk factor for accelerated PD progression and arteriosclerosis. The triple combination $\mathrm{LD} / \mathrm{CD} / \mathrm{EN}$ in one tablet is an essential step forward, since pill size and number of tablets taken are reduced. This formulation improved patients' acceptance and preference in addition to its proven better safety compared with tolcapone.

\section{Disclosures}

The author has no conflicts of interest to disclose.

\section{References}

1. Fahn S, Oakes D, Shoulson I, et al. Levodopa and the progression of Parkinson's disease. N Engl J Med. 2004;351(24):2498-2508.

2. Birkmayer W, Hornykiewicz O. [The L-3,4-dioxyphenylalanine (DOPA)-effect in Parkinson-akinesia]. Wien Klin Wochenschr. 1961;73:787-788.

3. Cotzias GC, Papavasiliou PS, Gellene R. Modification of Parkinsonism chronic treatment with L-dopa. N Engl J Med. 1969;280(7):337-345.

4. Müller T. Tolcapone in the management of Parkinson's disease. Aging Health. 2006;2(5):709-720.

5. Ruottinen HM, Rinne UK. COMT inhibition in the treatment of Parkinson's disease. J Neurol. 1998;245(11 Suppl 3):25-34.

6. Ceravolo R, Piccini P, Bailey DL, Jorga KM, Bryson H, Brooks DJ. 18F-dopa PET evidence that tolcapone acts as a central COMT inhibitor in Parkinson's disease. Synapse. 2002;43(3):201-207.

7. Russ H, Müller T, Woitalla D, Rahbar A, Hahn J, Kuhn W. Detection of tolcapone in the cerebrospinal fluid of parkinsonian subjects. Naunyn Schmiedebergs Arch Pharmacol. 1999;360(6):719-720.

8. Sawle GV, Burn DJ, Morrish PK, et al. The effect of entacapone (OR-611) on brain [18F]-6-L-fluorodopa metabolism: implications for levodopa therapy of Parkinson's disease. Neurology. 1994;44(7):1292-1297.

9. Hauser RA, Panisset G, Abbruzzese G, Manzione L, Dronamraju R, Kakarieka A. Improved symptom control with fixed dose levodopa/ carbidopa/entacapone versus conventional levodopa/carbidopa as firstline levodopa therapy in early Parkinson's disease patients. Mov Disord. 2008;23(Suppl 1):208

10. Olanow CW, Kieburtz K, Stern M, et al. Double-blind, placebocontrolled study of entacapone in levodopa-treated patients with stable Parkinson disease. Arch Neurol. 2004;61(10):1563-1568.

11. Müller T, Erdmann C, Muhlack S, Bremen D, Przuntek H, Woitalla D. Inhibition of catechol-O-methyltransferase contributes to more stable levodopa plasma levels. Mov Disord. 2006;21(3):332-336.

12. Olanow CW, Obeso JA. Pulsatile stimulation of dopamine receptors and levodopa-induced motor complications in Parkinson's disease: implications for the early use of COMT inhibitors. Neurology. 2000; 55(11 Suppl 4):S72-S77.

13. Müller T, Russ H. Levodopa, motor fluctuations and dyskinesia in Parkinson's disease. Expert Opin Pharmacother. 2006;7(13):1715-1730.

14. Riederer P, Gerlach M, Müller T, Reichmann H. Relating mode of action to clinical practice: dopaminergic agents in Parkinson's disease. Parkinsonism Relat Disord. 2007;13(8):466-479.

15. Nyholm D. Pharmacokinetic optimisation in the treatment of Parkinson's disease : an update. Clin Pharmacokinet. 2006;45(2):109-136.

16. Meiler B, Andrich J, Müller T. Rapid switch from oral antiparkinsonian combination drug therapy to duodenal levodopa infusion. Mov Disord. 2008;23(1):145-146.

17. Olanow CW, Stocchi F. COMT inhibitors in Parkinson's disease: can they prevent and/or reverse levodopa-induced motor complications? Neurology. 2004;62(1 Suppl 1):S72-S81.

18. Smith LA, Jackson MJ, Al Barghouthy G, et al. Multiple small doses of levodopa plus entacapone produce continuous dopaminergic stimulation and reduce dyskinesia induction in MPTP-treated drug-naive primates. Mov Disord. 2005;20(3):306-314.

19. Stocchi F, Vacca L, Ruggieri S, Olanow CW. Intermittent vs continuous levodopa administration in patients with advanced Parkinson disease: a clinical and pharmacokinetic study. Arch Neurol. 2005;62(6):905-910.

20. Lee MS, Kim HS, Cho EK, Lim JH, Rinne JO. COMT genotype and effectiveness of entacapone in patients with fluctuating Parkinson's disease. Neurology. 2002;58(4):564-567. 
21. Woitalla D, Karwasz R, Müller T, Przuntek H, Kuhn W. The activity of catechol-O-methyltransferase in parkinsonian patients with "on-off fluctuations". J Neural Transm. 2000;107(1):105-111.

22. Muhlack S, Woitalla D, Welnic J, Twiehaus S, Przuntek H, Müller T. Chronic levodopa intake increases levodopa plasma bioavailability in patients with Parkinson's disease. Neurosci Lett. 2004;363(3):284-287.

23. Müller T, Woitalla D, Saft C, Kuhn W. Levodopa in plasma correlates with body weight of parkinsonian patients. Parkinsonism Relat Disord. 2000;6(3):171-173.

24. Müller T, Erdmann C, Bremen D, et al. Impact of gastric emptying on levodopa pharmacokinetics in Parkinson disease patients. Clin Neuropharmacol. 2006;29(2):61-67.

25. Müller T, Woitalla D, Goetze O, Erdmann C. Entacapone improves absorption of a coadministered salt in patients with Parkinson's disease. Mov Disord. 2008;23(10):1458-1461.

26. Kortejarvi H, Urtti A, Yliperttula M. Pharmacokinetic simulation of biowaiver criteria: the effects of gastric emptying, dissolution, absorption and elimination rates. Eur J Pharm Sci. 2007;30(2):155-166.

27. Forsberg M, Lehtonen M, Heikkinen M, Savolainen J, Jarvinen T, Mannisto PT. Pharmacokinetics and pharmacodynamics of entacapone and tolcapone after acute and repeated administration: a comparative study in the rat. J Pharmacol Exp Ther. 2003;304(2):498-506.

28. Forsberg MM, Huotari M, Savolainen J, Mannisto PT. The role of physicochemical properties of entacapone and tolcapone on their efficacy during local intrastriatal administration. Eur J Pharm Sci. 2005;24(5):503-511.

29. Goetze O, Wieczorek J, Müller T, Przuntek H, Schmidt WE, Woitalla D. Impaired gastric emptying of a solid test meal in patients with Parkinson's disease using 13C-sodium octanoate breath test. Neurosci Lett. 2005;375(3):170-173.

30. Goetze O, Nikodem AB, Wiezcorek J, et al. Predictors of gastric emptying in Parkinson's disease. Neurogastroenterol Motil. 2006;18(5):369-375.

31. Lennernas H. Modeling gastrointestinal drug absorption requires more in vivo biopharmaceutical data: experience from in vivo dissolution and permeability studies in humans. Curr Drug Metab. 2007;8(7):645-657.

32. Thwaites DT, Anderson CM. H+-coupled nutrient, micronutrient and drug transporters in the mammalian small intestine. Exp Physiol. 2007;92(4):603-619.

33. Mannisto PT. Catechol O-methyltransferase: characterization of the protein, its gene, and the preclinical pharmacology of COMT inhibitors. Adv Pharmacol. 1998;42:324-328.

34. Müller T, Erdmann C, Muhlack S, et al. Pharmacokinetic behaviour of levodopa and 3-O-methyldopa after repeat administration of levodopa/ carbidopa with and without entacapone in patients with Parkinson's disease. J Neural Transm. 2006;113(10):1441-1448.

35. Müller T, Kolf K, Ander L, Woitalla D, Muhlack S. Catechol-Omethyltransferase inhibition improves levodopa-associated strength increase in patients with Parkinson disease. Clin Neuropharmacol. 2008;31(3):134-140.

36. Müller T, Ander L, Kolf K, Woitalla D, Muhlack S. Comparison of $200 \mathrm{mg}$ retarded release levodopa/carbidopa - with $150 \mathrm{mg}$ levodopa/carbidopa/entacapone application: pharmacokinetics and efficacy in patients with Parkinson's disease. J Neural Transm. 2007;114(11):1457-1462.

37. Fabbrini G, Juncos JL, Mouradian MM, Serrati C, Chase TN. 3-Omethyldopa and motor fluctuations in Parkinson's disease. Neurology. 1987;37(5):856-859.

38. Soares-da-Silva P, Parada A, Serrao P. The O-methylated derivative of L-DOPA, 3-O-methyl-L-DOPA, fails to inhibit neuronal and non-neuronal aromatic L-amino acid decarboxylase. Brain Res. 2000;863(1-2):293-297.

39. Arnsten AF, Li BM. Neurobiology of executive functions: catecholamine influences on prefrontal cortical functions. Biol Psychiatry. 2005;57(11):1377-1384.
40. Müller T. Role of homocysteine in the treatment of Parkinson's disease. Expert Rev Neurother. 2008;8(6):957-967.

41. Ben Shlomo Y, Marmot MG. Survival and cause of death in a cohort of patients with parkinsonism: possible clues to aetiology? J Neurol Neurosurg Psychiatry. 1995;58(3):293-299.

42. Gorell JM, Johnson CC, Rybicki BA. Parkinson's disease and its comorbid disorders: an analysis of Michigan mortality data, 1970 to 1990. Neurology. 1994;44(10):1865-1868.

43. Nakaso K, Yasui K, Kowa H, et al. Hypertrophy of IMC of carotid artery in Parkinson's disease is associated with L-DOPA, homocysteine, and MTHFR genotype. J Neurol Sci. 2003;207(1-2):19-23.

44. O'Suilleabhain PE, Sung V, Hernandez C, et al. Elevated plasma homocysteine level in patients with Parkinson disease: motor, affective, and cognitive associations. Arch Neurol. 2004;61(6):865-868.

45. Ozer F, Meral H, Hanoglu L, et al. Plasma homocysteine levels in patients treated with levodopa: motor and cognitive associations. Neurol Res. 2006;28(8):853-858.

46. Zoccolella S, Lamberti P, Iliceto G, et al. Plasma homocysteine levels in L-dopa-treated Parkinson's disease patients with cognitive dysfunctions. Clin Chem Lab Med. 2005;43(10):1107-1110.

47. Hassin-Baer S, Cohen O, Vakil E, et al. Plasma homocysteine levels and Parkinson disease: disease progression, carotid intima-media thickness and neuropsychiatric complications. Clin Neuropharmacol. 2006;29(6):305-311.

48. O’Suilleabhain PE, Oberle R, Bartis C, Dewey RB Jr, Bottiglieri T, az-Arrastia R. Clinical course in Parkinson's disease with elevated homocysteine. Parkinsonism Relat Disord. 2006;12(2):103-107.

49. Miller JW, Selhub J, Nadeau MR, Thomas CA, Feldman RG, Wolf PA. Effect of L-dopa on plasma homocysteine in PD patients: relationship to B-vitamin status. Neurology. 2003;60(7):1125-1129.

50. Woitalla D, Kuhn W, Müller T. MTHFR C677T polymorphism, folic acid and hyperhomocysteinemia in levodopa treated patients with Parkinson's disease. J Neural Transm Suppl. 2004; (68):15-20.

51. Müller T, Kuhn W. Tolcapone decreases plasma levels of S-adenosyl-Lhomocysteine and homocysteine in treated Parkinson's disease patients. Eur J Clin Pharmacol. 2006;62(6):447-450.

52. Nissinen E, Nissinen H, Larjonmaa H, et al. The COMT inhibitor, entacapone, reduces levodopa-induced elevations in plasma homocysteine in healthy adult rats. J Neural Transm. 2005;112(9):1213-1221.

53. Ostrem JL, Kang GA, Subramanian I, et al. The effect of entacapone on homocysteine levels in Parkinson disease. Neurology. 2005;64(8):1482.

54. Zesiewicz TA, Wecker L, Sullivan KL, Merlin LR, Hauser RA. The controversy concerning plasma homocysteine in Parkinson disease patients treated with levodopa alone or with entacapone: effects of vitamin status. Clin Neuropharmacol. 2006;29(3):106-111.

55. Lamberti P, Zoccolella S, Iliceto G, et al. Effects of levodopa and COMT inhibitors on plasma homocysteine in Parkinson's disease patients. Mov Disord. 2005;20(1):69-72.

56. Valkovic P, Benetin J, Blazicek P, Valkovicova L, Gmitterova K, Kukumberg P. Reduced plasma homocysteine levels in levodopa/ entacapone treated Parkinson patients. Parkinsonism Relat Disord. 2005;11(4):253-256

57. Zoccolella S, Lamberti P, Armenise E, et al. Plasma homocysteine levels in Parkinson's disease: role of antiparkinsonian medications. Parkinsonism Relat Disord. 2005;11(2):131-133.

58. Isobe C, Murata T, Sato C, Terayama Y. Increase of total homocysteine concentration in cerebrospinal fluid in patients with Alzheimer's disease and Parkinson's disease. Life Sci. 2005;77(15): 1836-1843.

59. Lee ES, Chen H, Soliman KF, Charlton CG. Effects of homocysteine on the dopaminergic system and behavior in rodents. Neurotoxicology. 2005;26(3):361-371.

60. Heider I, Lehmensiek V, Lenk T, Müller T, Storch A. Dopaminergic neurotoxicity of homocysteine and its derivatives in primary mesencephalic cultures. J Neural Transm Suppl. 2004;(68):1-13. 
61. Huang G, Dragan M, Freeman D, Wilson JX. Activation of catecholO-methyltransferase in astrocytes stimulates homocysteine synthesis and export to neurons. Glia. 2005;51(1):47-55.

62. Storch A, Blessing H, Bareiss M, et al. Catechol-O-methyltransferase inhibition attenuates levodopa toxicity in mesencephalic dopamine neurons. Mol Pharmacol. 2000;57(3):589-594.

63. Kuhn W, Woitalla D, Gerlach M, Russ H, Müller T. Tolcapone and neurotoxicity in Parkinson's disease. Lancet. 1998;352(9136):1313-1314.

64. Matsubara K, Aoyama K, Suno M, Awaya T. N-methylation underlying Parkinson's disease. Neurotoxicol Teratol. 2002;24(5):593-598.

65. Lee ES, Chen H, Soliman KF, Charlton CG. Effects of homocysteine on the dopaminergic system and behavior in rodents. Neurotoxicology. 2005;26(3):361-371.

66. Fuso A, Seminara L, Cavallaro RA, D’Anselmi F, Scarpa S. S-adenosylmethionine/homocysteine cycle alterations modify DNA methylation status with consequent deregulation of PS1 and BACE and beta-amyloid production. Mol Cell Neurosci. 2005;28(1):195-204.

67. Cavallaro RA, Fuso A, D’Anselmi F, Seminara L, Scarpa S. The effect of S-adenosylmethionine on CNS gene expression studied by cDNA microarray analysis. J Alzheimers Dis. 2006;9(4):415-419.

68. Hartz CS, Schalinske KL. Phosphatidylethanolamine N-methyltransferase and regulation of homocysteine. Nutr Rev. 2006;64(10 Pt 1):465-467.

69. Liu XX, Wilson K, Charlton CG. Effects of L-dopa treatment on methylation in mouse brain: implications for the side effects of L-dopa. Life Sci. 2000;66(23):2277-2288.

70. Morrison LD, Smith DD, Kish SJ. Brain S-adenosylmethionine levels are severely decreased in Alzheimer's disease. J Neurochem. 1996;67(3):1328-1331.

71. Müller T, Woitalla D, Hauptmann B, Fowler B, Kuhn W. Decrease of methionine and $\mathrm{S}$-adenosylmethionine and increase of homocysteine in treated patients with Parkinson's disease. Neurosci Lett. 2001;308(1):54-56.

72. Nagatsu T. Isoquinoline neurotoxins in the brain and Parkinson's disease. Neurosci Res. 1997;29(2):99-111.

73. Aoyama K, Matsubara K, Okada K, et al. N-methylation ability for azaheterocyclic amines is higher in Parkinson's disease: nicotinamide loading test. J Neural Transm. 2000;107(8-9):985-995.

74. Aoyama K, Matsubara K, Kondo M, et al. Nicotinamide-Nmethyltransferase is higher in the lumbar cerebrospinal fluid of patients with Parkinson's disease. Neurosci Lett. 2001;298(1):78-80.

75. Naoi M, Maruyama W, Nakao N, Ibi T, Sahashi K, Benedetti MS (R)salsolinol N-methyltransferase activity increases in parkinsonian lymphocytes. Ann Neurol. 1998;43(2):212-216.

76. Müller T, Sallstrom BS, Haussermann P, et al. Plasma levels of $\mathrm{R}$ - and S-salsolinol are not increased in "de-novo" Parkinsonian patients. J Neural Transm. 1998;105(2-3):239-246.

77. Müller T, Sallstrom BS, Haussermann P, Przuntek H, Rommelspacher H, Kuhn W. R- and S-salsolinol are not increased in cerebrospinal fluid of Parkinsonian patients. J Neurol Sci. 1999;164(2):158-162.

78. Brosnan JT, Jacobs RL, Stead LM, Brosnan ME. Methylation demand: a key determinant of homocysteine metabolism. Acta Biochim Pol. 2004;51(2):405-413.

79. Brooks DJ. Safety and tolerability of COMT inhibitors. Neurology. 2004;62(1 Suppl 1):S39-S46.
80. Durif F, Devaux I, Pere JJ, Delumeau JC, Bourdeix I. Efficacy and tolerability of entacapone as adjunctive therapy to levodopa in patients with Parkinson's disease and end-of-dose deterioration in daily medical practice: an open, multicenter study. Eur Neurol. 2001;45(2):111-118.

81. Gershanik O, Emre M, Bernhard G, Sauer D. Efficacy and safety of levodopa with entacapone in Parkinson's disease patients suboptimally controlled with levodopa alone, in daily clinical practice: an international, multicentre, open-label study. Prog Neuropsychopharmacol Biol Psychiatry. 2003;27(6):963-971.

82. Gordin A, Kaakkola S, Teravainen H. Clinical advantages of COMT inhibition with entacapone - a review. J Neural Transm. 2004;111 (10-11):1343-1363.

83. Illi A, Sundberg S, Ojala-Karlsson P, Scheinin M, Gordin A. Simultaneous inhibition of catecholamine-O-methylation by entacapone and neuronal uptake by imipramine: lack of interactions. Eur J Clin Pharmacol. 1996;51(3-4):273-276.

84. Koller W, Guarnieri M, Hubble J, Rabinowicz AL, Silver D. An openlabel evaluation of the tolerability and safety of Stalevo (carbidopa, levodopa and entacapone) in Parkinson's disease patients experiencing wearing-off. J Neural Transm. 2005;112(2):221-230.

85. Larsen JP, Worm-Petersen J, Siden A, Gordin A, Reinikainen K, Leinonen $\mathrm{M}$. The tolerability and efficacy of entacapone over 3 years in patients with Parkinson's disease. Eur J Neurol. 2003;10(2): 37-146.

86. Lyytinen J, Kaakkola S, Ahtila S, Tuomainen P, Teravainen H. Simultaneous MAO-B and COMT inhibition in L-Dopa-treated patients with Parkinson's disease. Mov Disord. 1997;12(4):497-505.

87. Martignoni E, Blandini F, Pacchetti C, Nappi G. COMT inhibition and safety. Funct Neurol. 2001;16(4 Suppl):135-140.

88. Rinne UK, Larsen JP, Siden A, Worm-Petersen J. Entacapone enhances the response to levodopa in parkinsonian patients with motor fluctuations. Nomecomt Study Group. Neurology. 1998;51(5):1309-1314.

89. Zijlmans JC, Debilly B, Rascol O, Lees AJ, Durif F. Safety of entacapone and apomorphine coadministration in levodopa-treated Parkinson's disease patients: pharmacokinetic and pharmacodynamic results of a multicenter, double-blind, placebo-controlled, cross-over study. Mov Disord. 2004;19(9):1006-1011.

90. Martignoni E, Cosentino M, Ferrari M, et al. Two patients with COMT inhibitor-induced hepatic dysfunction and UGT1A9 genetic polymorphism. Neurology. 2005;65(11):1820-1822.

91. Grosset KA, Reid JL, Grosset DG. Medicine-taking behavior: implications of suboptimal compliance in Parkinson's disease. Mov Disord. 2005;20(11):1397-1404.

92. Grosset KA, Grosset DG. Effect of educational intervention on medication timing in Parkinson's disease: a randomized controlled trial. $B M C$ Neurol. 2007;7:20.

93. Parkinson Study Group. Pramipexole vs levodopa as initial treatment for Parkinson disease: A randomized controlled trial. JAMA. 2000;284(15):1931-1938.

94. Rascol O, Brooks DJ, Korczyn AD, De Deyn PP, Clarke CE, Lang AE. A five-year study of the incidence of dyskinesia in patients with early Parkinson's disease who were treated with ropinirole or levodopa. 056 Study Group. N Engl J Med. 2000;342(20):1484-1491. 
